\title{
Amplitude Normalization of Dendritic EPSPs at the Soma of Binaural Coincidence Detector Neurons of the Medial Superior Olive
}

\author{
Bradley D. Winters, ${ }^{\star}$ Shan-Xue Jin, ${ }^{\star}$ Kenneth R. Ledford, and $\odot$ Nace L. Golding \\ University of Texas at Austin, Department of Neuroscience and Center for Learning and Memory, Austin, Texas 78712-0248
}

The principal neurons of the medial superior olive (MSO) encode cues for horizontal sound localization through comparisons of the relative timing of EPSPs. To understand how the timing and amplitude of EPSPs are maintained during propagation in the dendrites, we made dendritic and somatic whole-cell recordings from MSO principal neurons in brain slices from Mongolian gerbils. In somatic recordings, EPSP amplitudes were largely uniform following minimal stimulation of excitatory synapses at visualized locations along the dendrites. Similar results were obtained when excitatory synaptic transmission was eliminated in a low calcium solution and then restored at specific dendritic sites by pairing input stimulation and focal application of a higher calcium solution. We performed dual dendritic and somatic whole-cell recordings to measure spontaneous EPSPs using a dual-channel template-matching algorithm to separate out those events initiated at or distal to the dendritic recording location. Local dendritic spontaneous EPSP amplitudes increased sharply in the dendrite with distance from the soma (length constant, $53.6 \mu \mathrm{m}$ ), but their attenuation during propagation resulted in a uniform amplitude of $\sim 0.2 \mathrm{mV}$ at the soma. The amplitude gradient of dendritic EPSPs was also apparent in responses to injections of identical simulated excitatory synaptic currents in the dendrites. Compartmental models support the view that these results extensively reflect the influence of dendritic cable properties. With relatively few excitatory axons innervating MSO neurons, the normalization of dendritic EPSPs at the soma would increase the importance of input timing versus location during the processing of interaural time difference cues in vivo.

Key words: brainstem; coincidence detection; dendrites; medial superior olive; propagation; sound localization

Significance Statement

The neurons of the medial superior olive analyze cues for sound localization by detecting the coincidence of binaural excitatory synaptic inputs distributed along the dendrites. Previous studies have shown that dendritic voltages undergo severe attenuation as they propagate to the soma, potentially reducing the influence of distal inputs. However, using dendritic and somatic patch recordings, we found that dendritic EPSP amplitude increased with distance from the soma, compensating for dendritic attenuation and normalizing EPSP amplitude at the soma. Much of this normalization reflected the influence of dendritic morphology. As different combinations of presynaptic axons may be active during consecutive cycles of sound stimuli, somatic EPSP normalization renders spike initiation more sensitive to synapse timing than dendritic location.

\section{Introduction}

In mammals, the principal neurons of the medial superior olive (MSO) are a key component in the processing of interaural time differences (ITDs), the binaural cues that reflect differences in the location of low-frequency $(<2 \mathrm{kHz})$ sounds along the horizontal plane (Grothe, 2003). MSO neurons perform this computation through coincidence detection. They increase their firing rate according to the level of synchrony in the arrival times of EPSPs driven by sounds at the two ears.
Correspondence should be addressed to Dr. Nace L. Golding, University of Texas at Austin, Department of Neuroscience and Center for Learning and Memory, 1 University Station C7000, Austin, TX 78712-0248. E-mail: golding@austin.utexas.edu.

S.-X. Jin's present address: Department of Developmental, Molecular and Chemical Biology, Tufts University School of Medicine, Boston, MA 02116.

DOI:10.1523/JNEUROSCI.3110-16.2017

Copyright $@ 2017$ the authors $\quad 0270-6474 / 17 / 373138-12 \$ 15.00 / 0$ 
To maintain fine temporal resolution of coincidence detection in MSO neurons, EPSPs must rise and decay quickly so that their window for temporal and spatial summation is narrow. MSO neurons express the GluA3 and GluA4 flop splice variants of AMPARs and omit GluA2 subunits (Caicedo and Eybalin, 1999; Schmid et al., 2001), a subunit combination associated with receptors exhibiting high calcium permeability and rapid kinetics (Lomeli et al., 1994; Geiger et al., 1995). AMPARs with similar features are consistently found in brainstem auditory neurons that encode temporal features of sound with precision (Smith et al., 2000; Gardner et al., 2001).

MSO principal neurons have a stereotyped bipolar architecture, with each dendrite being $\sim 100-200 \mu \mathrm{m}$ in length. Their ipsilateral and contralateral excitatory inputs are segregated onto lateral and medial dendrites, respectively (Lindsey, 1975; Cant and Casseday, 1986; Smith et al., 1993; Beckius et al., 1999). Excitatory boutons are distributed all along the shafts of the nonspiny dendrites and soma and exhibit multiple release sites per bouton (Clark, 1969; Perkins, 1973; Lindsey, 1975; BrunsoBechtold et al., 1990). In vitro experiments have estimated the minimum number of excitatory axons per side to be between 2 and 4 (Couchman et al., 2010), but each axon is highly branched (Smith et al., 1993; Beckius et al., 1999) and makes multiple synapses per dendrite (Clark, 1969).

Integration of excitatory inputs along dendrites affects the resolution and accuracy of binaural coincidence detection, as EPSPs originating distally would be expected to undergo more severe cable filtering than their proximal counterparts, resulting in strong attenuation in amplitude, delays in rise time, and prolongation of duration (Rinzel and Rall, 1974). Several factors reduce distortions in EPSP timing in MSO neurons. Mature MSO principal neurons exhibit sparsely branched, large-caliber dendrites (Smith, 1995; Rautenberg et al., 2009), which reduce axial current flow and accelerate the decay rate of EPSPs (Agmon-Snir et al., 1998; Mathews et al., 2010). The interplay between synaptic excitation and voltagegated channels also plays a key role in offsetting the effects of cable filtering. MSO neurons exhibit a somatically biased gradient of KCNA1 (Kv1) potassium channels that actively repolarize EPSPs, particularly those whose duration is increased by cable filtering (Scott et al., 2005; Mathews et al., 2010). Kv1 channels thus maintain a uniform duration of EPSPs independent of synapse location in the dendrites. MSO neurons also express a high density of hyperpolarization and cyclic nucleotide gated $(\mathrm{HCN})$ channels, which mediate a strong resting conductance, thus imparting fast rising and decaying voltage changes (Khurana et al., 2011, 2012; Baumann et al., 2013).

The combined effects of KCNA1 and HCN channels create strong attenuation of voltages between the dendrites and soma (Mathews et al., 2010), potentially reducing the influence of distal synapses. Further, voltage-gated $\mathrm{Na}^{+}$channels are not strongly expressed in the dendrites of MSO neurons, and dendritic electrogenesis has not been observed (Scott et al., 2010). In the present study, we asked how distal synaptic events effectively reach the soma of MSO neurons to contribute to binaural coincidence detection. We provide evidence that the amplitude of EPSPs increases distally along the dendrites and compensates for the attenuation of EPSPs as they propagate along the dendrites to the soma. Thus, the functional impact of different excitatory axons is determined primarily by the number of synapses made and their timing of activation, but not by their dendritic location.

\section{Materials and Methods}

Tissue preparation. All animal procedures were approved by the University of Texas at Austin Animal Care and Use Committee in accordance with the guidelines of the National Institutes of Health. Mongolian gerbils of both sexes were used at 16-25 d old. These animals were bred at the University of Texas at Austin or procured from Charles River Laboratories. Animals were decapitated under isoflurane anesthesia and the brain quickly removed in oxygenated ACSF at $32^{\circ} \mathrm{C}$. ACSF contained the following (in mM): $125 \mathrm{NaCl}, 2.5 \mathrm{KCl}, 1.5 \mathrm{CaCl}_{2}, 1.5 \mathrm{MgSO}_{4}, 25$ $\mathrm{NaHCO}_{3}, 1.25 \mathrm{NaH}_{2} \mathrm{PO}_{4}, 25$ dextrose, pH 7.40 with $\mathrm{NaOH}, \sim 310$ $\mathrm{mmol} / \mathrm{kg}$. The brainstem was blocked, and horizontal slices containing the MSO were cut using a vibrating microtome $(200 \mu \mathrm{m}$ thickness; VT1200S, Leica). The slices were incubated in ACSF at $35^{\circ} \mathrm{C}$ for $30 \mathrm{~min}$. and then maintained at room temperature until they were transferred to the stage for recordings.

Electrophysiology. MSO principal cells were visualized using infrared differential interference contrast (DIC) microscopy (Axioskop 2 FS Plus with $40 \times$ or $60 \times$ objective, Zeiss) and were selected based on their location in the slice, soma shape, dendritic arborization, and responses to current steps (Scott et al., 2005).

Recordings were made with thick-walled borosilicate glass pipettes with resistances of $2-4 \mathrm{M} \Omega$ for somatic recordings and $6-11 \mathrm{M} \Omega$ for dendritic recordings (1.5 or $1.65 \mathrm{OD}$, Sutter Instruments). Pipettes were filled with an internal solution containing the following (in $\mathrm{mm}$ ): 115 K-gluconate, $4.42 \mathrm{KCl}, 0.5 \mathrm{EGTA}, 10 \mathrm{HEPES}, 10 \mathrm{Na}_{2}$-phosphocreatine, $\sim 45$ sucrose, 4 Mg-ATP, $0.3 \mathrm{Na}-\mathrm{GTP}, \mathrm{pH} 7.30$ with $\mathrm{KOH}, \sim 300 \mathrm{mmol} /$ $\mathrm{kg}$. Strychnine ( $1 \mu \mathrm{M}$, Sigma-Aldrich) was added to the ACSF to block glycinergic inhibition during all recordings. The temperature of the ACSF was maintained at $35 \pm 0.1^{\circ} \mathrm{C}$ during all recordings.

Recordings were made with Dagan BVC-700A amplifiers in whole-cell current-clamp mode. Electrical stimulation was performed using a constant current stimulator (Digitimer). Data were low-pass filtered at $5 \mathrm{kHz}$ and acquired to computer at $50 \mathrm{kHz}$ using custom macros for IgorPro (Wavemetrics). A liquid junction potential of $10 \mathrm{mV}$ was not corrected. Recordings were abandoned if series resistance increased $>25 \mathrm{~m} \Omega$ for somatic recordings or $>50 \mathrm{M} \Omega$ for dendritic recordings.

Theta electrode stimulation. Animals used for these experiments were age postnatal day 20 (P20) on average. During whole-cell somatic recordings, theta-glass electrodes ( $\sim 1 \mu \mathrm{m}$ tip, Warner Instruments, $2 \mathrm{~mm}$ OD) were used to electrically stimulate local axonal inputs at multiple locations along dendrites visualized with DIC optics. In these experiments, the $\mathrm{Ca}^{2+}$ concentration in the ACSF was lowered $\left(1 \mathrm{mM} \mathrm{Ca}^{2+}, 2 \mathrm{~mm}\right.$ $\mathrm{Mg}^{2+}$ ) to increase synaptic failure rates. Even under these conditions, there was a steep transition from a few failures to all failures, and stimulated sites with synaptic failure rates $\geq 15 \%$ emerged as a reasonable cutoff for minimal stimulation in this configuration. After failures were removed, the remaining traces $(20-40)$ were averaged and used for further analysis. Experiments in which synaptic stimulation sites were varied from distal to proximal locations were alternated with those where sites were varied from proximal to distal locations.

Focal calcium application. Somatic whole-cell current-clamp recordings were made from MSO neurons from P21 gerbils on average. To evoke synaptic vesicle release at restricted dendritic locations, slices were bathed in low $\mathrm{Ca}^{2+}\left(0.2 \mathrm{~mm} \mathrm{Ca}^{2+}, 2.8 \mathrm{~mm} \mathrm{Mg}^{2+}\right)$ ACSF to block synaptic transmission. Calcium was then restored locally at specific dendritic sites with a higher $\mathrm{Ca}^{2+}$ solution via pressure pulses (Pressure System IIe, Toohey) applied through a 3-5 $\mathrm{M} \Omega$ patch pipette. The puffing solution contained the following (in mM): $150 \mathrm{NaCl}, 1.5 \mathrm{KCl}, 25$ dextrose, 10 HEPES, $1 \mathrm{MgCl}_{2}, 4 \mathrm{CaCl}_{2}$, $\mathrm{pH} 7.40, \sim 310 \mathrm{mmol} / \mathrm{kg}$. The $\mathrm{Ca}^{2+}$ puffs were applied while excitatory inputs were electrically stimulated with a glass stimulating electrode $(\sim 50$ $\mu \mathrm{m}$ tip diameter) placed between midline and the ipsilateral medial nucleus of the trapezoid body. The puffer pipette was placed near the dendrite, and the location and puff intensity ( $\sim 4-6 \mathrm{~ms}$ at $10-15 \mathrm{psi})$ were adjusted until a response was obtained exhibiting a failure rate of $\geq 15 \%$. Calcium application was triggered $40 \mathrm{~ms}$ before the electrical stimulation. Such responses could be eliminated by slowly retracting the calcium application pipette. Experiments in which dendritic puffing sites were sampled in a distal to proximal progression were alternated with those sampling in the opposite 
direction. After failures were removed, the remaining traces (20-40) were averaged and used for analysis.

Dual dendritic-somatic recordings. A custom 2-channel sliding template search algorithm was used to detect spontaneous EPSPs (sEPSPs) simultaneously in the soma and dendrites. Multiple records 7 or $9 \mathrm{~s}$ in length were analyzed. The algorithm scales an EPSP template to minimize the sum of squared errors at each time point and then generates a "detection criterion" trace for each channel (Clements and Bekkers, 1997). Events were classified as EPSPs if the detection criterion in either the somatic or dendritic channel exceeded a threshold value of 6 . All events were visually confirmed. The threshold value used was arrived at empirically by balancing the number of false positives, which had to be visually eliminated, with a small number of false negatives that would go undetected. This was accomplished by manual inspection of a large number of EPSPs from both the somatic and dendritic traces after template searches at different thresholds. Events were analyzed according to individual parameters (amplitude, half-width, time to peak, rise time), as well as the relative attenuation between dendritic and somatic recording sites (EPSP $\left.{ }_{\text {soma }} / \mathrm{EPSP}_{\text {dendrite }}\right)$. EPSPs were then sorted according to degree of attenuation and EPSPs arising from nonrecorded dendrites, where $\mathrm{EPSP}_{\text {soma }} / \mathrm{EPSP}_{\text {dendrite }}>1$ were removed. Of the remaining EPSPs from the recorded dendrite, where $\mathrm{EPSP}_{\text {soma }} / \mathrm{EPSP}_{\text {dendrite }}$ varied from 0 to 1 , we selected a population of highly attenuated EPSPs $\left(\mathrm{EPSP}_{\text {soma }} / \mathrm{EPSP}_{\text {dendrite }}<0.15\right)$ as having arisen near or more distal to the dendritic recording site. These EPSPs were manually inspected before the final acceptable population was averaged. Restricting analysis to even higher levels of attenuation gave similar results, but the resulting decrease in the number of averaged events increased the influence of recording noise.

We could not measure somatodendritically propagating sEPSPs accurately due to their small size in the distal dendrites $(<0.1 \mathrm{mV})$. As an alternative, we made simultaneous somatic and dendritic recordings and stimulated excitatory inputs to the opposite dendrite electrically using a glass stimulating electrode (i.e., ipsilateral stimulation for medial dendritic recordings and contralateral stimulation for lateral dendritic recordings). In some recordings, we additionally characterized the forward propagation of EPSPs from dendrite to the soma by injecting simulated EPSCs (simEPSCs) through the dendritic recording pipette. Some of these data are from additional analyses of recordings that were previously published (Mathews et al., 2010).

Modeling. An MSO neuron model was constructed with NEURON software, version 7.4 (Hines and Carnevale, 1997), consisting of a soma, axon, and two dendrites. The basic model dimensions were as follows: soma, length $=25 \mu \mathrm{m}$, diameter $=15 \mu \mathrm{m}$, Nseg $=1$; axon, length $=400$ $\mu \mathrm{m}$, diameter $=2 \mu \mathrm{m}, \mathrm{Nseg}=51$; dendrite, total length $=150 \mu \mathrm{m}$ (unless otherwise noted), segment length $=10 \mu \mathrm{m}$, diameter $=3 \mu \mathrm{m}$ (unless otherwise noted), Nseg $=10$. Only the dendrite in which measurements were taken varied in diameter or length as noted in the results. All compartments were assigned a membrane resistance of $200 \Omega \times \mathrm{cm}$ and a membrane capacitance of $1 \mu \mathrm{F} / \mathrm{cm}^{2}$. The soma, axon, and dendrites were assigned a leak channel with a reversal potential of $E_{L}=-58$ $\mathrm{mV}$. The maximum conductances were $G_{L}=1 \mathrm{mS} / \mathrm{cm}^{2}$ in the soma and axon and $G_{L}=2 \mathrm{mS} / \mathrm{cm}^{2}$ in the dendrites. The axon and dendrites were also given a low-voltage activated potassium channel $\left(\mathrm{K}_{\mathrm{LVA}}\right)$ with kinetics originally described by Rothman and Manis (2003) and modified to NEURON's NMODL language by Zhou et al. (2005). All other aspects of $K_{L V A}$ channel expression were derived from Mathews et al. (2010). The $\mathrm{K}_{\mathrm{LVA}}$ reversal potential for both soma and dendrites was set to $E_{K}=$
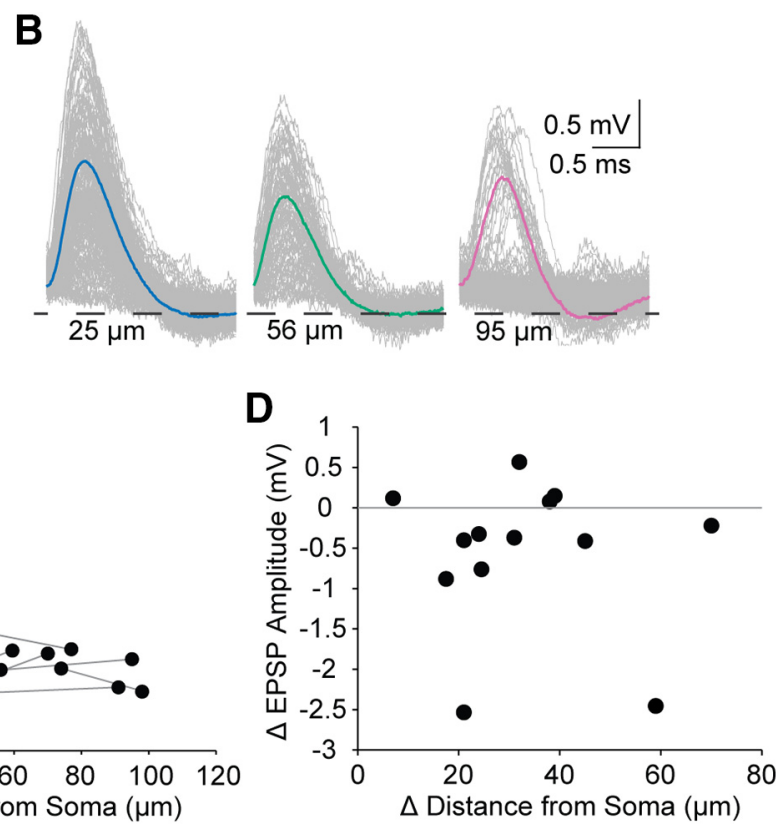

Figure 1. Theta electrode-evoked EPSP amplitudes are largely independent of distance from the soma beyond $35 \mu \mathrm{m}$.

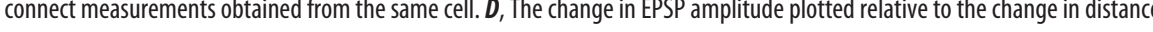
$0 \mathrm{mV}$ change. Points above this line indicate an increased amplitude with increased distance from the soma. Points below the line $-106 \mathrm{mV}$, and the maximum conductance was set to $G_{K}=17 \mathrm{mS} / \mathrm{cm}^{2}$ at the soma. In the dendrites, $\mathrm{K}_{\mathrm{LVA}}$ density decreased exponentially as previously described (Mathews et al., 2010), via the equation $G_{K}=$ $17\left(0.6 e^{-\frac{x}{74}}-0.05\right) \mathrm{mS} / \mathrm{cm}^{2}$, where 74 is in $\mu \mathrm{m}$ and is the model space constant from Mathews et al. (2010). This equation was based on an empirical fit to the voltage-dependent sharpening of EPSPs observed in paired dendritic and somatic recordings. Alpha synapses were then placed centrally in each of the dendrite segments, each with a maximum conductance of $0.4 \mathrm{mS} / \mathrm{cm}^{2}$ and a time constant of $0.2 \mathrm{~ms}$. The effects of each synapse along the dendrite were examined locally in the dendrite segment where the synaptic conductance originated and at the soma. The basic model had a resting membrane potential of $-65 \mathrm{mV}$ and a membrane time constant of $0.25 \mathrm{~ms}$.

Statistical analyses. All data were analyzed in IgorPro or Prism 7 (GraphPad). Data are mean \pm SEM and compared using Student's $t$ tests (paired or unpaired as noted). The two-sample Kolmogorov-Smirnov test was used to compare sEPSP amplitude distributions. Nonlinear regression was performed in Prism using the model for one-phase exponential decay $\mathrm{Y}=(\mathrm{Y} 0-$ plateau $) \times \exp (-\mathrm{K} \times \mathrm{X})+$ plateau or exponential growth $\mathrm{Y}=\mathrm{Y} 0 \times \exp (\mathrm{K} \times x)$ where tau $(\lambda)$ is $1 / \mathrm{K}$. Parameter confidence intervals (CIs) provided are $95 \%$ asymmetric likelihoods. Fit parameters were compared in Prism using the Extra sum-of-squares $F$ test. Significance was assessed using an $\alpha$ level of 0.05 .

\section{Results}

To measure EPSPs originating from known locations in MSO principal cells, we made whole-cell current-clamp recordings from the soma of MSO neurons whose dendrites could be visualized for distances up to $100 \mu \mathrm{m}$ from the soma. A theta glass stimulating electrode $(\sim 1 \mu \mathrm{m}$ tip diameter $)$ was placed within 4 $\mu \mathrm{m}$ of the dendrite, and the stimulus strength was adjusted to evoke minimal EPSPs (failure rate $>15 \%$ ) in the presence of $1 \mu \mathrm{M}$ strychnine to block glycinergic inhibition. We stimulated 2-3 locations per neuron at distances of 25-98 $\mu \mathrm{m}$ from the somatic 

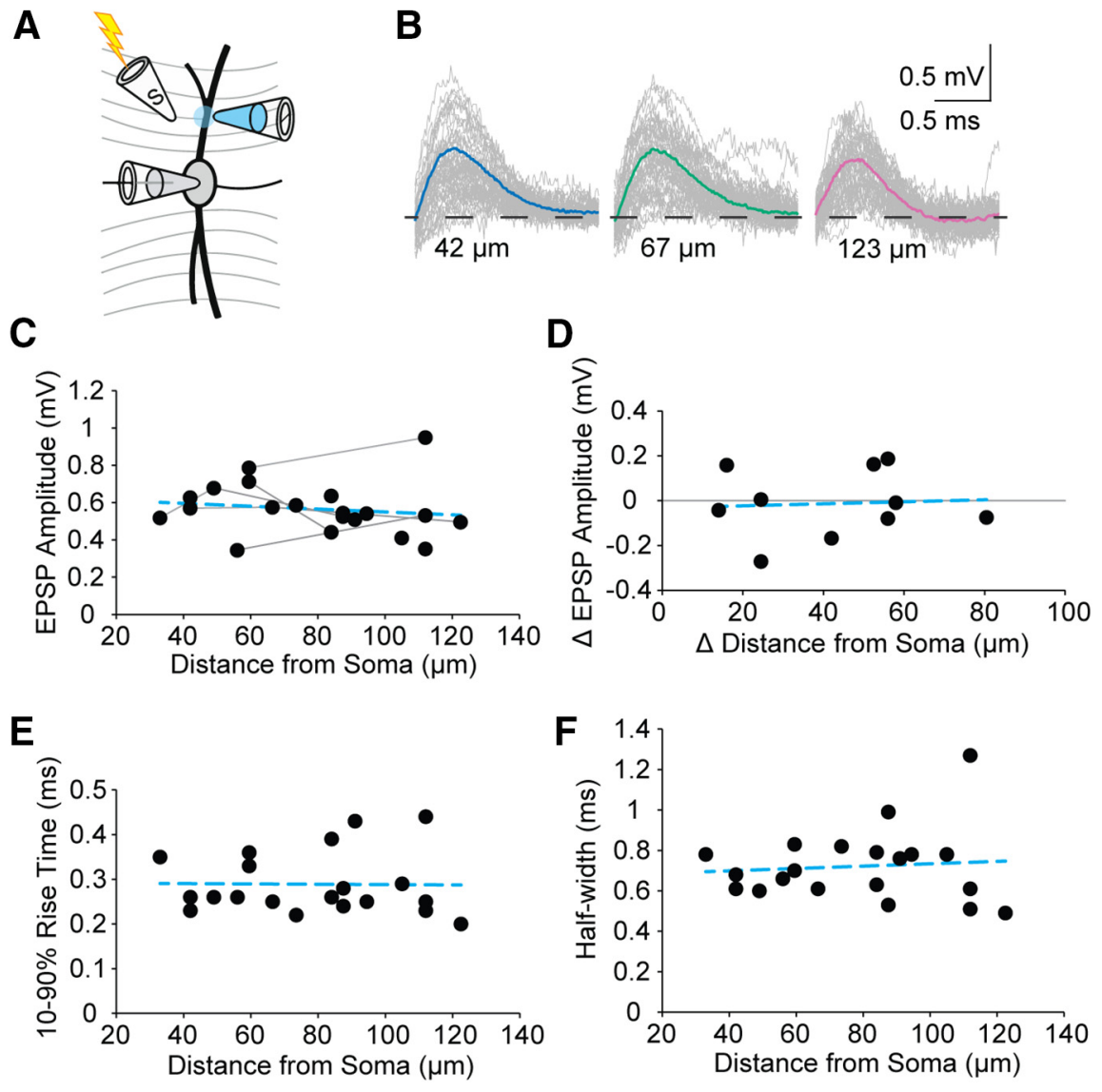

Figure 2. Evoked EPSPs localized by focal dendritic $\mathrm{Ca}^{2+}$ application are similar at the soma regardless of propagation distance. $A$, Schematic diagram showing paired $\mathrm{Ca}^{2+}$ puffing and electrical stimulation taking place in low $(0.2 \mathrm{~mm}) \mathrm{Ca}^{2+}$ ACSF. $\boldsymbol{B}$, Representative average traces from a single neuron at 3 different dendritic $\mathrm{Ca}^{2+}$ puffing locations showing that the EPSP amplitude measured at the soma was independent of dendritic origin. C, Somatic EPSP amplitudes plotted as function of the distance propagated from the dendritic site of origin. Gray lines connect measurements obtained from the same cell. Blue dashed line indicates linear fit; slope $=-0.0008 \mathrm{mV} / \mu \mathrm{m}, Y 0=0.63 \mathrm{mV}, R^{2}=0.02, n=20 . D$, The change in EPSP amplitude plotted relative to the change in distance from the soma for $\mathrm{Ca}^{2+}$ puffing recordings that sampled multiple locations on the same cell. Gray line is at $0 \mathrm{mV}$ change. Points above this line indicate an increased amplitude with increased distance from the soma. Points below the line indicate a decrease. Blue dashed line indicates linear fit; slope $=0.0004 \mathrm{mV} / \mu \mathrm{m}, \mathrm{Y} 0=-0.03 \mathrm{mV}, R^{2}=0.00, n=10$ comparisons. $\boldsymbol{E}$, The $10 \%-90 \%$ rise time for responses in C. Blue dashed line indicates linear fit; slope $=0.0000 \mathrm{mV} / \mu \mathrm{m}, Y 0=0.3$ $\mathrm{ms}, R^{2}=0.00, n=20 . \boldsymbol{F}$, Half-width for responses in $\boldsymbol{C}$. Blue dashed line indicates linear fit; slope $=0.0006 \mathrm{mV} / \mu \mathrm{m}, \mathrm{Y} 0=0.7$ $\mathrm{ms}, R^{2}=0.01, n=20$.

recording electrode. Across all dendritic sites, minimal evoked EPSPs recorded at the soma had amplitudes ranging from $0.79-$ $3.34 \mathrm{mV}$ and an average amplitude of $1.53 \pm 0.17 \mathrm{mV}$ (Fig. $1 A-C$, $n=17$ locations from 7 cells). When we stimulated within $35 \mu \mathrm{m}$ from the soma, EPSP amplitudes could be larger and were more variable, ranging from 1.50 to $3.34 \mathrm{mV}$ and averaging $2.29 \pm 0.32$ $\mathrm{mV}(n=5)$. Beyond $35 \mu \mathrm{m}$ from the soma, the amplitude variability reduced by $66 \%$ and the average was $1.21 \pm 0.11 \mathrm{mV}(n=$ 12). For recordings that sampled multiple dendritic locations on the same neuron, the amplitude was not strongly affected by increasing distance from the soma. The average change in amplitude with distance between stimulation locations was $-0.57 \pm 0.26 \mathrm{mV}$ with the average distance between stimulation locations being $33.00 \pm 4.81 \mu \mathrm{m}$ and the average change in amplitude per micrometer $-0.020 \pm 0.010 \mathrm{mV} / \mu \mathrm{m}$ (Fig. $1 D, n=13$ comparisons).

Because of the nature of electrical stimulation and axonal branching, theta electrode stimulation experiments likely activated multiple boutons, possibly located at different dendritic distances from the soma. To refine our synaptic analysis, we made somatic whole-cell current-clamp recordings and lowered bath $\mathrm{Ca}^{2+}$ to 0.2 $\mathrm{mm}$ to inhibit synaptic release throughout the slice. We then focally restored synaptic transmission to local areas of the dendrite, visualized under DIC optics, by pairing focal application of a higher $\mathrm{Ca}^{2+}$ solution (4 mM) with broad electrical stimulation of excitatory inputs (Fig. 2A). In these experiments, stimulation occurred between the midline of the slice and the ipsilateral medial nucleus of the trapezoid body while blocking glycinergic inhibition with strychnine $(1 \mu \mathrm{M})$. Stimulus magnitude was adjusted to produce minimal EPSPs with at least a $15 \%$ failure rate, yielding EPSP amplitudes ranging from 0.34 to $0.95 \mathrm{mV}$. We probed locations along dendrites in this way from 33 to 123 $\mu \mathrm{m}$ from the somatic recording electrode (Fig. 2B, $C$, average amplitude $0.57 \pm 0.03$ $\mathrm{mV}, n=20$ locations from 13 cells). The amplitude of EPSPs recorded at the soma was largely independent of distance along the dendrite where they were initiated (Fig. 2C). In a number of experiments, we were able to compare EPSP size from multiple dendritic locations in the same cell. We again found that there was very little change with distance. The average change in amplitude with increasing distance between puffing locations was $0.01 \pm$ $0.05 \mathrm{mV}$, and the average change in distance between stimulation locations was $42.40 \pm 6.92 \mu \mathrm{m}$ (Fig. $2 D, n=10 \mathrm{com}-$ parisons). The average change in amplitude per micrometer was $0.000 \pm 0.002$ $\mathrm{mV} / \mu \mathrm{m}$. Interestingly, the shape of EPSPs was also uniform during propagation from the dendrites to the soma. The 10\%$90 \%$ rise time and half-width of EPSPs showed little distance dependence, averaging $0.29 \pm 0.02 \mathrm{~ms}$ and $0.72 \pm 0.04 \mathrm{~ms}$, respectively (Fig. 2E, $F, n=20$ ).

The uniformity of the amplitude of somatic EPSPs arising from different dendritic locations is surprising given the strong attenuation that has been observed in EPSPs propagating from the dendrites to the soma in previous studies (Mathews et al., 2010), suggesting a distance-dependent compensatory mechanism. To further address this question, we made dual somatic and dendritic patch-clamp recordings from MSO neurons and recorded sEPSPs. The sEPSPs were detected and sorted according to degree of attenuation between the dendrites and soma using a custom 2-channel template matching algorithm (see Materials and Methods; Fig. $3 A, B$ ). The sEPSPs were blocked by CNQX $(10 \mu \mathrm{M})$, indicating they are mediated by AMPARs (Fig. 3C,E). There were 117 events recorded in CNQX versus 4081 events in ACSF, yielding a false-positive rate of $2.9 \%$. It is possible these few events may indeed have been EPSPs from synapses in the middle of the slice that had not been fully blocked by the CNQX, but these events could not be excluded.

The average amplitudes of all sEPSPs, recorded at either the dendrite or soma, were not affected by the voltage-gated $\mathrm{Na}^{+}$ 
A

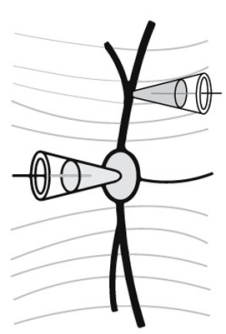

B

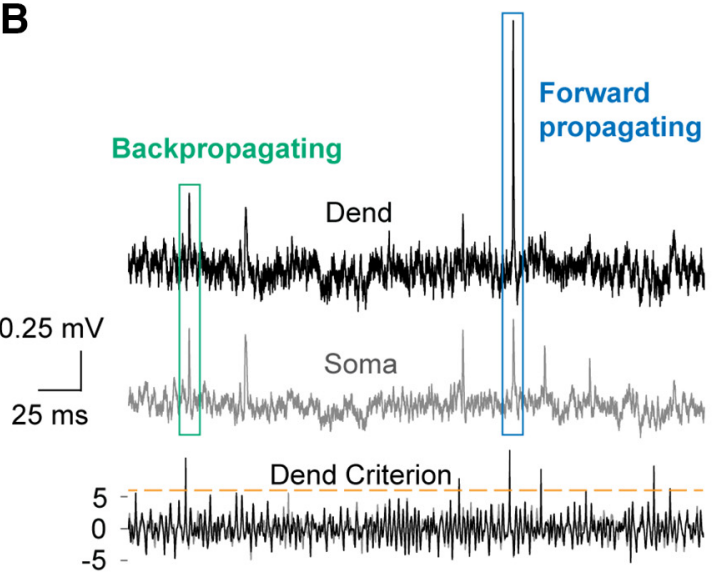

\section{E}

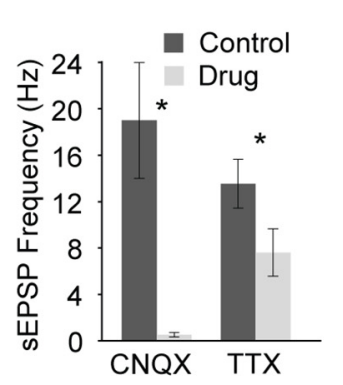

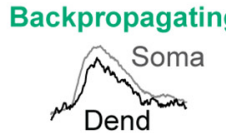

Forward propagating

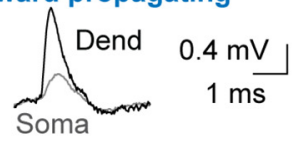

Forward propagating
C
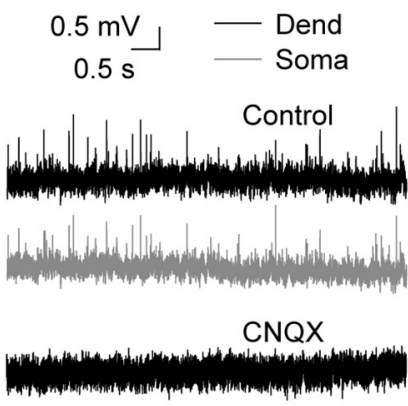

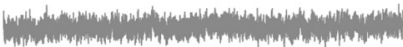

D

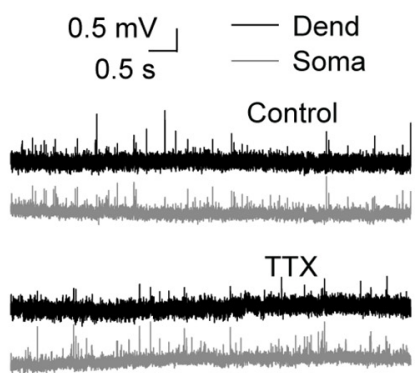

G

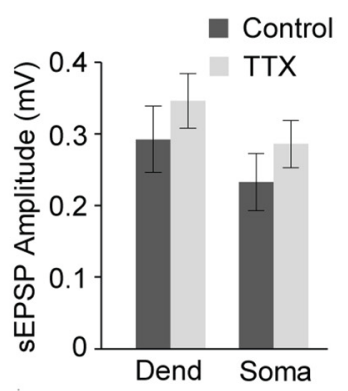

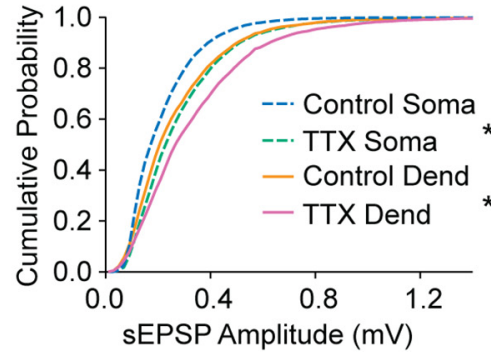

Figure 3. Dual-channel sliding template detection of sEPSPs. A, Schematic diagram of the dual somatic/dendritic whole-cell recordings used and example traces, enlarged from boxes shown in $\boldsymbol{B}$, of two events showing the propagation direction based on the relative amplitudes of somatic and dendritic EPSPs. $\boldsymbol{B}$, A sliding template algorithm was performed simultaneously for dendritic (black) and somatic (gray) recordings, yielding corresponding traces of the detection criterion (bottom, only dendritic shown; however, both were searched simultaneously). Dashed orange line indicates the selection criteria of 6. C, Example traces showing the effects of AMPAR block with bath-applied CNQX (10 $\mu \mathrm{M})$. D, Example traces showing the effects of bath-applied TTX ( $1 \mu \mathrm{M})$. $E$, Group averages showing the effects of CNQX ( $n=6$ cells, $p=0.004$ ) and TTX ( $n=7$ cells, $p=0.03$ ) on frequency of all sEPSPs. $F$, Group data showing the effects of TTX on all sEPSP amplitudes at the dendritic ( $n=7$ cells, $p=0.29)$ and somatic $(n=7$ cells, $p=0.14)$ locations. G, Cumulative probability of all sEPSP event amplitudes showing the effects of TTX at the somatic $(p \ll 0.001$, $n=6186 \times 5307$, Kolmogorov-Smirnov test $)$ and dendritic $(p \ll 0.001, n=6186 \times 5307$, Kolmogorov-Smirnov test $)$ locations.

channel blocker TTX ( $1 \mu \mathrm{M}$, Fig. $3 D, F)$, indicating that sEPSPs in MSO slices are likely to be from unitary vesicle fusions (miniature EPSPs [mEPSPs]). There was also no amplitude difference between the somatic and dendritic locations when all events were sampled (Fig. 3F). However, the frequency of events was reduced by TTX (Fig. 3E). This finding was surprising given that the cochlear nuclei, thought to provide the only excitatory input to the MSO (Perkins, 1973; Kiss and Majorossy, 1983; Schofield and Cant, 1991), are not present in our preparation. However, in the presence of TTX, there was also no drop in the cumulative frequency distribution of the sEPSP amplitudes as would be expected if there was a population of larger, action potential-driven events in the control condition. There was indeed a small, but significant, shift toward larger amplitudes with TTX in the distribution (Fig. 3G).

To isolate local dendritic sEPSPs, we sorted all sEPSPs, detected in either the somatic or dendritic recording site, for the $15 \%$ most attenuated events (EPSP soma $/ \mathrm{EPSP}_{\text {dendrite }}$ ), which would have originated near or distal to the dendritic recording site. In agreement with previous work using simulated EPSPs (Mathews et al., 2010), we observed large-amplitude attenuation of sEPSPs as they propagated to the soma (Fig. $4 A, B$ ). Indeed, the ratio of the somatic to dendritic amplitude decreased with distance from the soma to the dendritic recording location with a length constant $(\lambda)$ of $68.0 \mu \mathrm{m}$ (Fig. $4 C$ ). We used the midpoint of the sEPSP rise to examine the relative timing of sEPSPs at the dendritic and somatic recording sites. As expected, the difference increased with distance from the soma (Fig. 4E). Using this slope, we estimated the forward conduction velocity of the dendrite to be $0.8 \mathrm{~m} / \mathrm{s}$. The kinetics of EPSPs were largely uniform in the propagated sEPSPs (Fig. 4D). The ratio of the somatic to dendritic half-width did not exhibit an effect of distance to the dendritic recording location (Fig. $4 F$ ). There did not appear to be any systematic differences between events in the lateral versus medial dendrites, and the datasets were combined for analysis (Fig. 4C-F). 
A

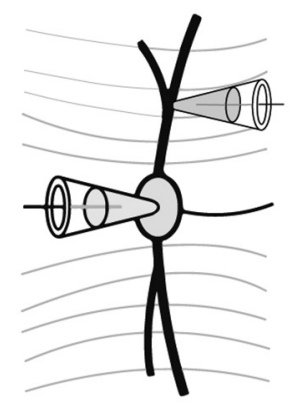

D
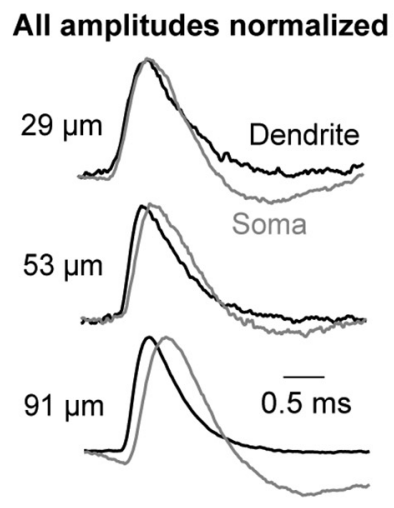

B

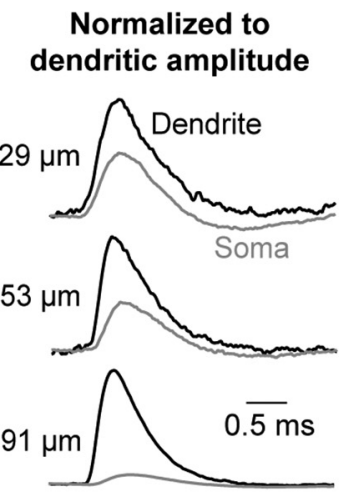

E

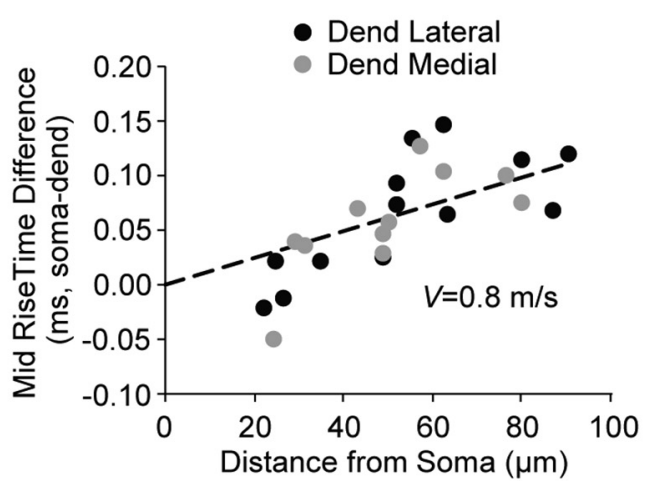

C

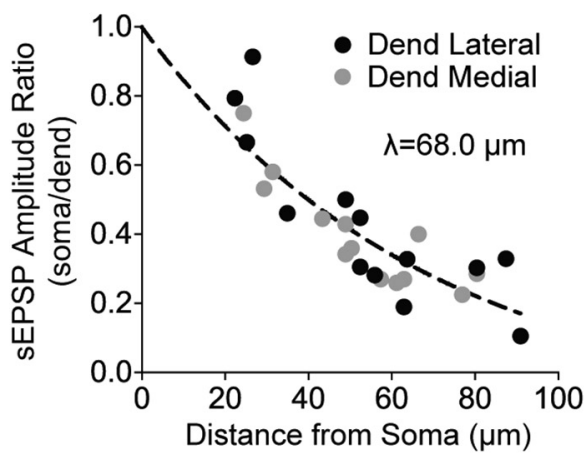

$\mathbf{F}$

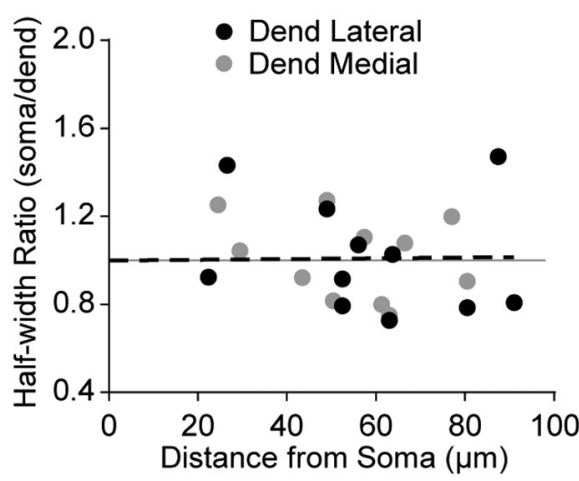

Figure 4. Dendritically localized SEPSPs are strongly attenuated during propagation to the soma but maintain a uniform shape. A, Schematic diagram showing the experimental layout. $B$, Average traces for the $15 \%$ most attenuated sEPSPs from three different cells. Traces normalized to the amplitude of the dendritic sEPSP (black) illustrating large attenuation of the somatic potential (gray) with increasing distance from the soma. C, The ratio of somatic to dendritic average amplitudes for the $15 \%$ most attenuated sEPSPs as a function of distance from the soma to the dendritic recording pipette. Black symbols represent recordings from lateral dendrites. Gray symbols represent recordings from medial dendrites. Dashed line indicates one phase exponential decay; $\lambda=68.0$, Cl 39.5-163.8 $\mu \mathrm{m}$, plateau $=-0.12$, Cl 39.53-163.80, $R^{2}=0.77, n=26$, constrained to 0,1 . $\boldsymbol{D}$, Representative average traces for the three cells shown in $\boldsymbol{B}$ with amplitudes normalized to 1 to illustrate shape differences. $\boldsymbol{E}$, Difference in the time at midpoint of the SEPSP rise (at half-amplitude) between the dendritic and somatic recording sites for events shown in $\boldsymbol{C}$. Dashed line indicates linear fit; slope $=0.00124 \mathrm{mV} / \mu \mathrm{m}, R^{2}=-0.48, n=24$, constrained to 0,0 , velocity $=0.8, \mathrm{Cl} 0.7-1.0 \mathrm{~m} / \mathrm{s}$. $\boldsymbol{F}$, Half-width ratio for sEPSPs shown in $\boldsymbol{C}$. Dashed line indicates exponential growth; $\lambda=5907, \mathrm{CI} 591-\infty \mu \mathrm{m}, R^{2}=-0.01, n=23$, constrained to 0,1 .

The attenuation of sEPSPs along the dendrites was strongly dependent on the direction of propagation. However, the attenuation of sEPSPs propagating from the soma to the dendrites was problematic to assess because the amplitudes of sEPSPs at the soma $(\sim 0.2 \mathrm{mV})$ were already near the noise floor of the recording even before undergoing further attenuation in the opposite dendrite. To overcome this technical limitation, in a subset of dual somatic and dendritic recordings from MSO neurons, we electrically stimulated excitatory inputs targeting the dendrite opposite from the one bearing the dendritic recording pipette (Fig. $5 A$ ). With this configuration, evoked EPSPs first arrived at the soma $(9.07 \pm 1.19 \mathrm{mV})$ and underwent additional attenuation along their way to the dendritic recording location (Fig. $5 B$ ). The ratio of the dendritic to somatic amplitude decreased with distance from the soma to the dendritic recording location with a length constant of $76.4 \mu \mathrm{m}$ (Fig. 5C). Consistent with predictions from cable theory that somatodendritic propagation is more efficient than dendrosomatic propagation and is dependent on both electrotonic properties and dendritic morphology (Roth and Häusser, 2001; Golding et al., 2005; SchmidtHieber et al., 2007) the ratio fits were significantly different (Fig. 4C; $p<0.0001, F_{(2,34)}=26.65$, two-parameter comparison with $\mathrm{K}$ and plateau). The difference between the midpoint of the evoked EPSP rise at half-amplitude increased with distance from the soma (Fig. $5 D, E)$. Using this slope, we estimated the centrifugal conduction velocity of the dendrite to be $1.2 \mathrm{~m} / \mathrm{s}$. This is in close agreement with the previously reported action potential conduction velocity in the MSO of $1.0 \mathrm{~m} / \mathrm{s}$ (Scott et al., 2010). This fit, however, was not significantly different from the dendrosomatic direction (Fig. $4 E ; p=$ $0.086, F_{(1,34)}=3.13,1$-factor comparison of slope). With increasing distance from the soma, the half-width ratio of the evoked EPSPs increased (Fig. 5D,F). This is in contrast to events propagating from the dendrite to the soma (Fig. $4 F ; p=0.0003, F_{(1,33)}=16.47$, oneparameter comparison of $\mathrm{K})$. There did not appear to be any systematic differences between events in the lateral versus medial dendrites (Fig. 5C,E, F).

Further analyses of the top 15\% most attenuated dendrosomatic propagating sEPSPs revealed that the amplitudes of local sEPSPs originating in the dendrites increased dramatically with distance from the soma (Fig. $6 A, B$ ) with a length constant of $53.6 \mu \mathrm{m}$, whereas the amplitude of these same events after propagation to the soma showed little distance dependence (Fig. $6 \mathrm{C}$; average at soma $0.20 \pm 0.01 \mathrm{mV}$ ). Likewise, with analysis of the five largest dendritic events for each cell, we found that the average amplitude increased with distance from the soma with a similar length constant of 41.5 $\mu \mathrm{m}$ (Fig. $6 E$ ). There did not appear to be any systematic differences between events in the lateral versus medial dendrites (Fig. 6C,E). The cumulative probability of sEPSP amplitudes also displayed marked 
A

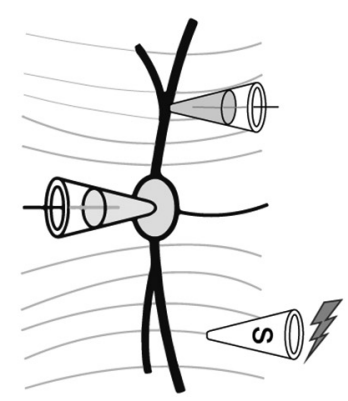

D All amplitudes normalized

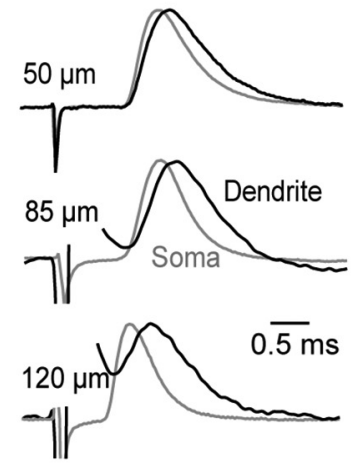

B

Normalized to somatic amplitude

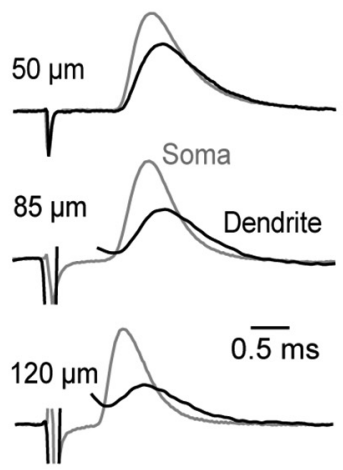

C

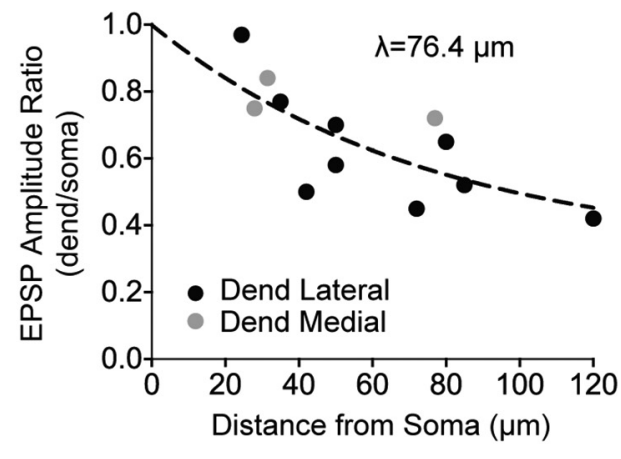

E

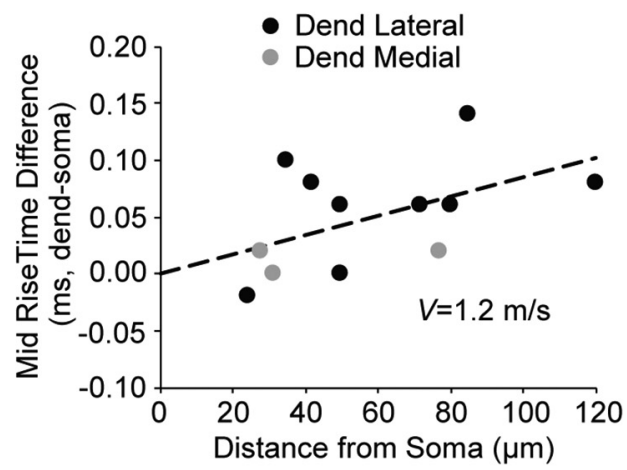

F

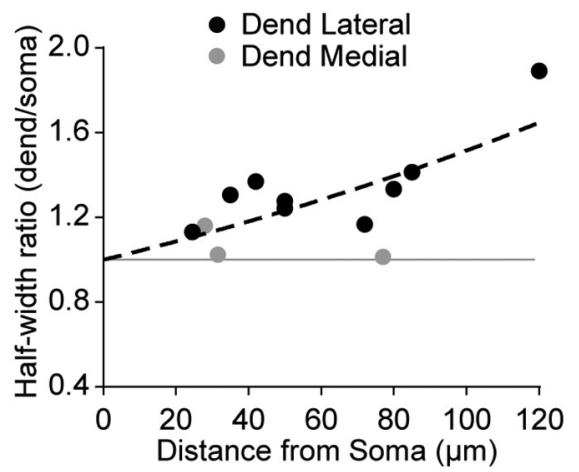

Figure 5. Evoked EPSPs propagating from the soma and dendrites undergo temporal distortions. $\boldsymbol{A}$, Schematic diagram showing the experimental layout. $\boldsymbol{B}$, Representative average traces for EPSPs evoked in the lateral dendrite from three different cells normalized to the amplitude of the somatic EPSP (gray). The dendritically recorded EPSP (black) attenuates more strongly with increasing distance from the soma. Some stimulus artifacts were removed for clarity. $C$, The ratio of dendritic to somatic average amplitudes for evoked EPSPs as a function of distance from the soma to the dendritic recording pipette. Black symbols represent lateral dendritic recordings. Gray symbols represent medial dendritic recordings. Dashed line indicates one phase exponential decay; $\lambda=$ 76.4 , Cl 21.0 -317,828 $\mu \mathrm{m}$, plateau $=0.31, \mathrm{Cl}-\infty-0.63, R^{2}=0.55, n=12$, constrained to $0,1 . \boldsymbol{D}$, Representative average traces for the three cells shown in $\boldsymbol{B}$ with amplitudes normalized to 1 to illustrate the shape differences. $\boldsymbol{E}$, Difference in the time at midpoint of the evoked EPSP rise (at half-amplitude) between the dendritic and somatic recording sites for events shown in $C$. Dashed line indicates linear fit; slope $=0.00085 \mathrm{mV} / \mu \mathrm{m}, R^{2}=0.24, n=12$, constrained to 0, 0, velocity $=1.2, \mathrm{Cl} 0.8-2.3 \mathrm{~m} / \mathrm{s}$. F, Half-width ratio for EPSPs shown in C. Dashed line indicates exponential growth; $\lambda=240.5$, Cl 190.4-339.6 $\mu \mathrm{m}, R^{2}=0.49, n=12$, constrained to 0,1 .

distance dependence when grouped by distance from the soma (Fig. 6D).

To probe the effects of local passive membrane properties alone on the distance dependence of local EPSP amplitude, in a subset of dual dendritic and somatic recordings, we injected identical $400 \mathrm{pA}$ simEPSCs through the dendritic recording pipette (Fig. $6 F$ ). We found that the amplitude of the potential elicited at the dendritic location increased with distance from the soma with a length constant of $97.2 \mu \mathrm{m}$ (Fig. $6 G, H$ ). This fit was not different from the sEPSP amplitudes (Fig. $6 C ; p=0.730, F_{(1,38)}=$ 0.1212 , one-parameter comparison of $\mathrm{K}$ ). Also, similar to our findings from sEPSPs (Fig. 6C), the amplitude of the propagated simEPSCs at the soma exhibited very little distance dependence (Fig. $6 \mathrm{H}$; average at soma $1.68 \pm 0.13 \mathrm{mV}$ ) and the slope linear fit was not different from the $\operatorname{sEPSPs}\left(p=0.111, F_{(1,38)}=2.658\right.$, one-parameter comparison of slope).

To better understand the morphological parameters that might contribute to the normalization of EPSP amplitudes at the soma and the increasing EPSP amplitudes observed locally in the dendrites, we constructed a simple compartmental model consisting of a soma and two identical, uniform dendrites $3 \mu \mathrm{m}$ in diameter and $150 \mu \mathrm{m}$ in length. In addition to passive leak channels, the model contained a gradient of low voltage-activated $\mathrm{K}^{+}$ channels distributed at threefold higher density at the soma vs the distal dendrites (see Materials and Methods) (Mathews et al., 2010). As expected, when dendritic diameter was decreased, local EPSPs in response to excitatory synaptic activation increased in amplitude (Fig. $7 A, B$ ), but not as quickly as the normalized fit to the observed sEPSPs (Fig. 7B, thick black line). At the soma, decreasing dendrite diameter reduced the amplitude of propagated EPSPs (Fig. 7B). Shortening the synapse-bearing dendrite also led to modest increases in local dendritic EPSP amplitude (Fig. $7 C, D$ ), although these EPSPs propagated more efficiently to the soma (Fig. $7 D$, green and orange thin lines). By contrast, dendritic EPSPs were highly sensitive to gradual changes in diameter: in a model with $150 \mu \mathrm{m}$ dendrites exhibiting a linear taper from 3 to $0.5 \mu \mathrm{m}$ only in the dendrite where measurements were made (Fig. 7E), the amplitude of local dendritic EPSPs increased sharply with distance from the soma (Fig. $7 F$ ). Despite the large local amplitudes, propagated events were largely unaffected by changing the amount of taper (Fig. $7 F$ ).

To examine whether differences in synaptic conductance might also explain our observations, we increased the synaptic conductance of dendritic synapses in our uniform dendrite model linearly from twofold to fourfold (Fig. 7G). In these simulations, a fourfold increase in synaptic conductance matched or exceeded the normalized fit to the dendritic sEPSP data (Fig. $7 \mathrm{H}$, thick black line); however, in contrast to the sEPSP data, the 
A

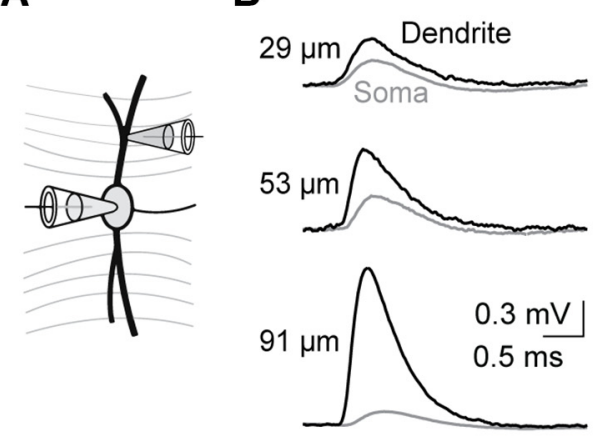

D

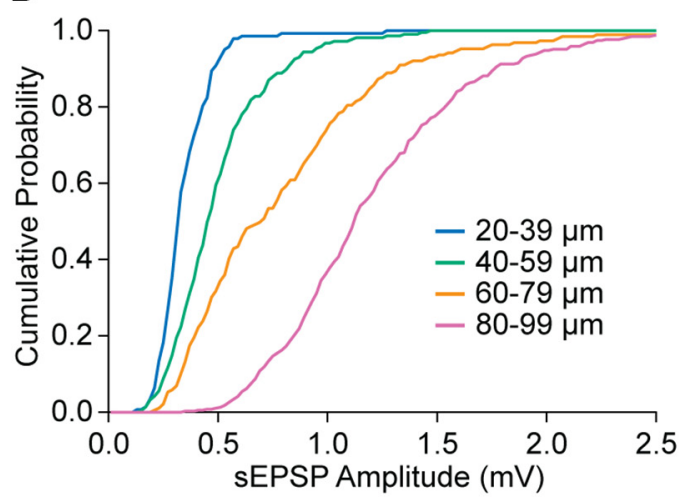

C
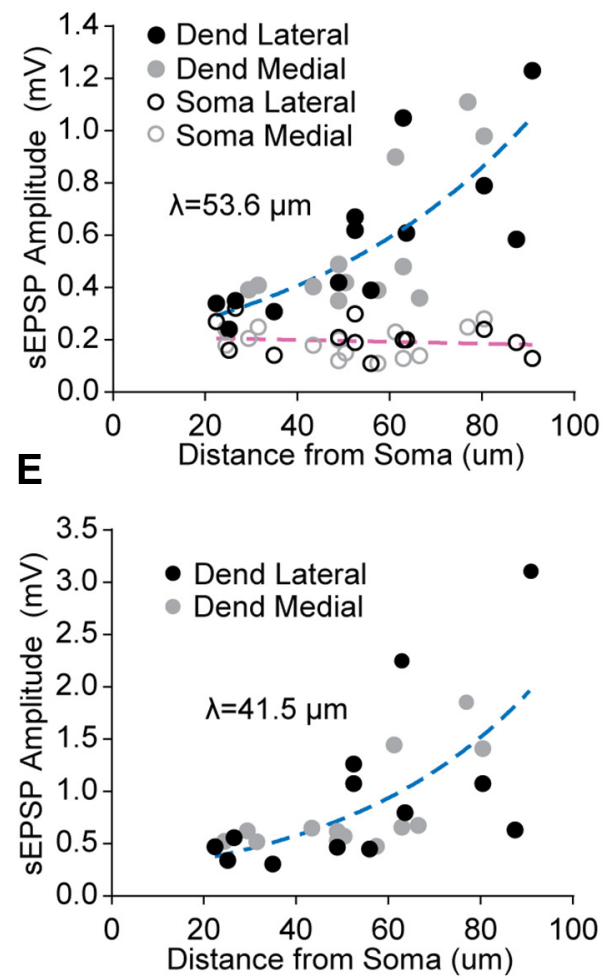

$\mathbf{F}$

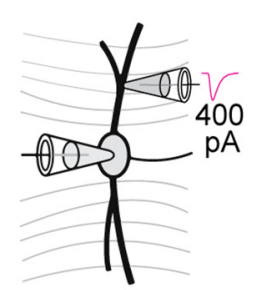

G
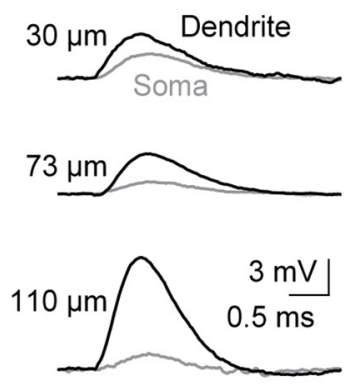

H

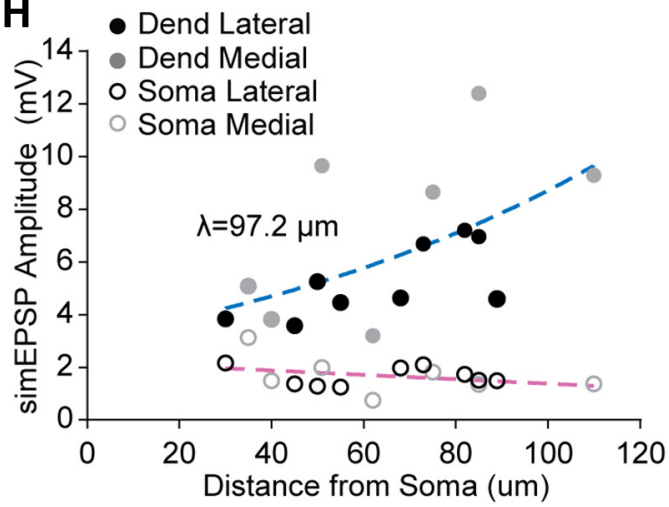

Figure 6. Local sEPSP amplitude increases with distance from the soma. $\boldsymbol{A}$, Schematic diagram showing the experimental layout. $\boldsymbol{B}$, Representative average traces for the $15 \%$ most attenuated (between recording sites) sEPSPs from three different cells. Dendritic SEPSPs (black) attenuate more strongly at more distal locations, resulting in somatic sEPSPs of similar amplitude (gray). C, Amplitudes for the $15 \%$ most attenuated sEPSPs at the dendritic (filled) and somatic (open) recording locations plotted relative to the distance from the soma to the dendritic recording location. Blue dashed line indicates exponential growth; $\lambda=53.6, \mathrm{Cl} 38.9-83.3 \mu \mathrm{m}, \mathrm{Y} 0=0.2 \mathrm{mV}, R^{2}=0.58, n=26$. Purple dashed line indicates linear fit; slope $=-0.0004 \mathrm{mV} / \mu \mathrm{m}, \mathrm{Y} 0=0.2 \mathrm{mV}$, $R^{2}=0.02, n=26 . C, E, H$, Black symbols represent lateral dendritic recordings. Gray symbols represent medial dendritic recordings. $D$, Cumulative probability of the $15 \%$ most attenuated sEPSP event amplitudes binned into four groups based on distance from the soma to the dendritic recording location (Kolmogorov-Smirnov tests: $20-39$ vs $40-59, p \ll 0.001, n=142 \times 215 ; 40-59$ vs $60-79, p \ll 0.001, n=215 \times 189 ; 60-79$ vs $80-99, p \ll 0.001, n=189 \times 388)$. $\boldsymbol{E}$, Amplitudes for the average of the five largest of the $15 \%$ most attenuated sEPSPs for each cell in C $p$ lotted relative to the distance from the soma to the dendritic recording location. Dashed line indicates exponential growth; $\lambda=41.48, C 126.49-80.09 \mu \mathrm{m}, Y 0=0.2 \mathrm{mV}, R^{2}=0.44, n=26 . F, S c h e m a t i c$ diagram showing dendritic simulated EPSC injection (400 pA). G, Representative average traces for the simEPSPs from three different cells. $\boldsymbol{H}$, Amplitudes for the simEPSPs at the dendritic (filled) and somatic (open) recording locations plotted relative to the distance from the soma to the dendritic recording location. Blue dashed line indicates exponential growth; $\lambda=97.2, \mathrm{Cl} 52.2-608.1$ $\mu \mathrm{m}, \mathrm{Y} 0=3.1 \mathrm{mV}, R^{2}=0.32, n=16$. Purple dashed line indicates linear fit; slope $=-0.0083 \mathrm{mV} / \mu \mathrm{m}, \mathrm{Y} 0=2.2 \mathrm{mV}, R^{2}=0.12, n=16$.

somatic EPSPs also increased in amplitude as a function of synapse distance from the soma (Fig. $7 H$ ).

Finally, we tested whether synaptic inputs onto small dendritic branches could, by virtue of their large local input resistance, give rise to the large spontaneous EPSPs observed in distal dendritic recordings (e.g., Fig. $6 D, E$ ). To address this question, we added a 30- $\mu \mathrm{m}$-long, $1-\mu \mathrm{m}$-diameter branch to our uniform 3- $\mu \mathrm{m}$-diameter, $150-\mu \mathrm{m}$-long dendrite model at different distances from the soma (Fig. 8A). Introduction of an excitatory conductance at the midpoint of the branch (branch synapse) generated large local EPSPs, but the transfer of voltage to the dendritic trunk attenuated the amplitude. The amplitude in the trunk was location-dependent, increasing with distance from the soma (Fig. $8 B$ ) similar to the uniform dendrite model (Fig. $7 B$ ). The branch synapse EPSP underwent slightly more attenuation than that from a synapse onto the main dendritic trunk (trunk synapse) at the same distance from the soma (15 $\mu \mathrm{m}$ beyond the dendritic recording location). Ultimately, the amplitudes of EPSPs originating in the branch or the trunk were similar after propagation to the soma (Fig. $8 B, C$ ). Thus, whereas den- 

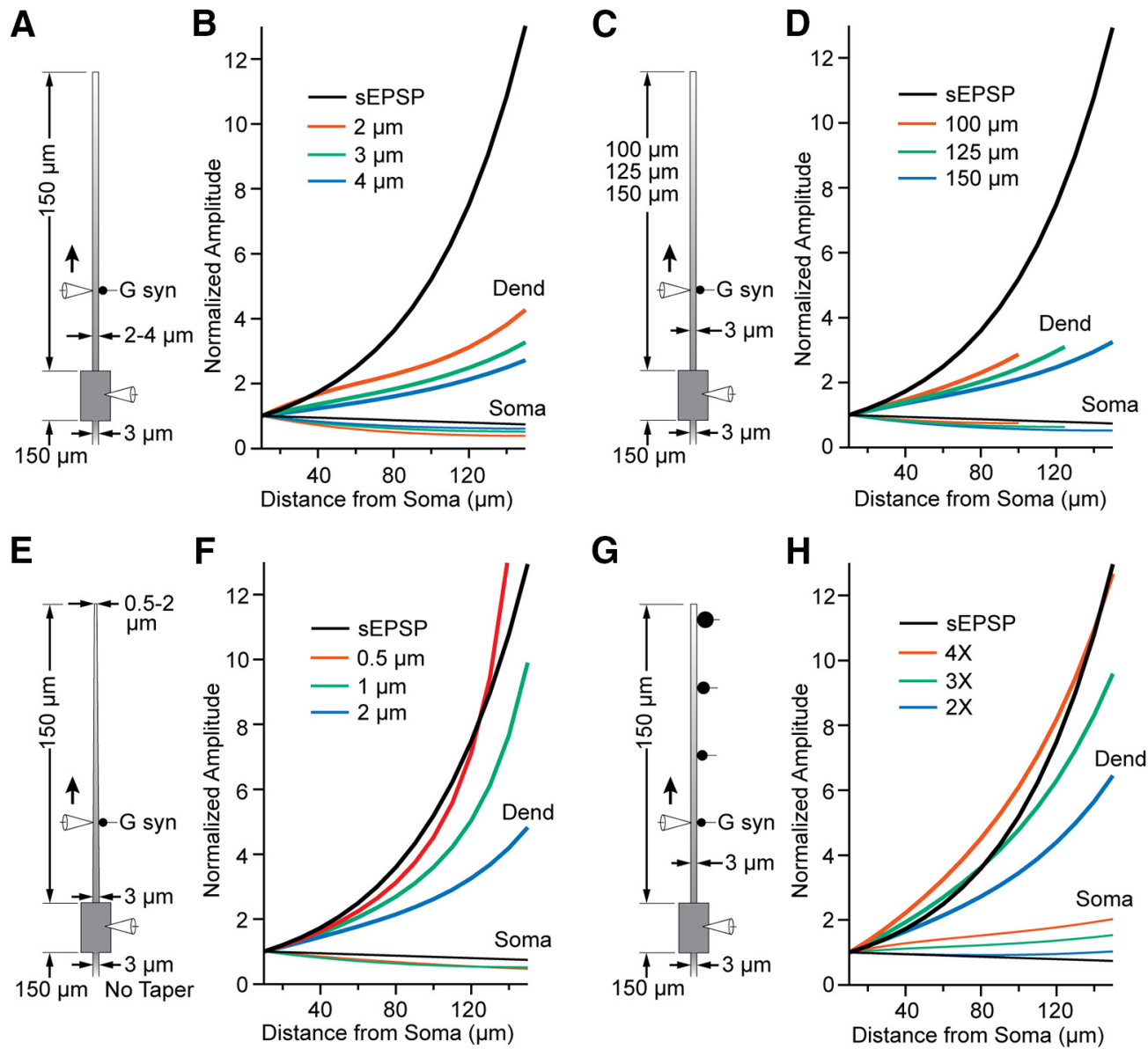

Figure 7. Morphological and synaptic effects on EPSP amplitudes in a model MSO neuron. $\boldsymbol{A}$, Diagram showing a model with $150-\mu \mathrm{m}$-long dendrites where only the dendrite in which measurements were made varied in diameter. $\boldsymbol{B}$, Modeling results for dendrite diameters of 2,3 , and $4 \mu \mathrm{m}$ and fits to sEPSP data from Figure $6 C$. Local amplitude in dendrite (thick lines), and amplitude at soma (thin lines), are plotted relative to the distance from the soma to the $\alpha$ synapse. C, Diagram showing a model with 3- $\mu$ m-diameter dendrites where the dendrite in which measurements were made varied in length. $\boldsymbol{D}$, Modeling results for dendrites 100,125 , and $150 \mu \mathrm{m}$ long. $\boldsymbol{E}$, Diagram showing a model with $150-\mu \mathrm{m}$-long dendrites where only the dendrite in which measurements were made tapers. $\boldsymbol{F}$, Modeling results for dendrites that tapered from 3- $\mu \mathrm{m}$-diameter to $0.5-, 1-$, and $2-\mu \mathrm{m}$-diameter. $\mathbf{G}$, Diagram showing a model with 3- $\mu \mathrm{m}$-diameter, $150-\mu \mathrm{m}$-long dendrites in which the synaptic conductance increases with distance from the soma. $\boldsymbol{H}$, Modeling results for twofold, threefold, and fourfold increases in synaptic conductance.

dritic morphology clearly influences the amplitude of local EPSPs, the amplitude normalization of EPSPs at the soma appears to be relatively insensitive to at least first-order branching complexity.

\section{Discussion}

The principal neurons of the MSO are one of several classes of neurons in auditory brainstem pathways that perform computations on synaptic information requiring submillisecond temporal precision. These neurons exhibit specialized intrinsic electrical properties that improve temporal precision of EPSPs propagating along their dendrites, but such mechanisms impose strong attenuation that would differentially impact more distal dendritic synapses. Here, we show that the amplitude of dendritic EPSPs increases with distance from the soma (Fig. 6C-E), which counteracts the strong amplitude attenuation along the dendrites and confers a uniform amplitude of EPSPs at the soma (Figs. $1 C$, $2 C, 6 C, H)$. Further, we show that somatic EPSPs appear highly consistent in their time course after propagation to the soma (Figs. 2E, F, 4F). The gradient in EPSP amplitude along the dendrites helps impart parity among synapses along the dendritic arbor in their ability to drive action potential firing and may be an important feature of coincidence detection in these neurons, en- suring that spike initiation is more sensitive to input timing than dendritic location.

\section{Excitatory synaptic inputs to MSO dendrites}

Our method for detecting sEPSPs simultaneously at the somatic and dendritic recording sites allowed us to record many smaller events that would have gone undetected at the soma due to their strong attenuation in the dendrites. We found that the amplitude of these events was only $\sim 0.2 \mathrm{mV}$ at the soma, regardless of whether the event was estimated to arise from a proximal versus distal dendritic location (Fig. 6C). The average amplitude of sEPSPs in either the dendrites or soma was similar with or without TTX (Fig. 3F), consistent with the fact that the cell bodies of bushy cells are not retained in MSO horizontal slices. Thus, these events can be considered mEPSPs. It is not clear why the frequency of events was reduced by TTX (Fig. 3E) but may reflect generalized changes in the slice over longer experiments. Using synaptic stimulation paired with local calcium application to localize synaptic release, we also found that the amplitude of minimal EPSPs did not depend on dendritic location (Fig. $2 C, D$ ), but the events were $\sim 2.5$ times larger than sEPSPs recorded at the soma, possibly reflecting an experimental bias favoring dendritic locations yielding larger, more readily observable EPSPs at the 
A

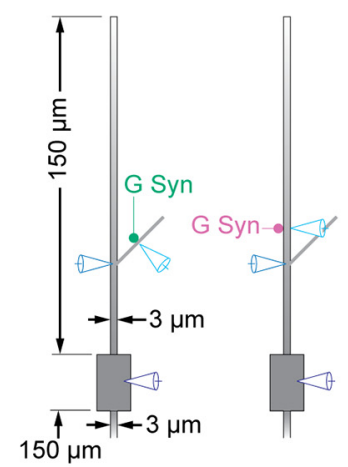

B

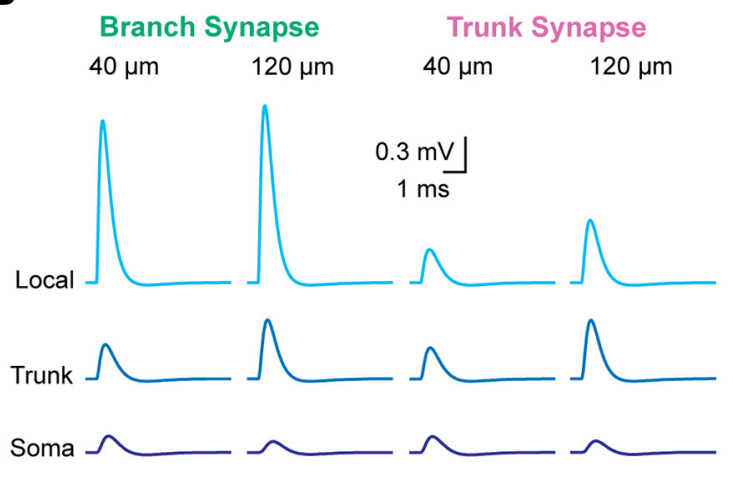

C

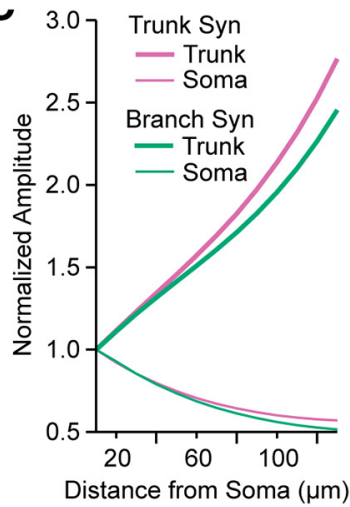

Figure 8. Effects on local EPSP amplitude of small dendritic branches in a model MSO neuron. $A$, Diagrams showing models with 3- $\mu \mathrm{m}$-diameter, 150 - $\mu \mathrm{m}$-long dendrites and a $1-\mu \mathrm{m}$-diameter, $30-\mu \mathrm{m}$-long branch at a variable distance from the soma. The synapse location is either at the midpoint of the branch, $15 \mu \mathrm{m}$ from the dendritic recording location on the trunk (left), or on the trunk itself $15 \mu \mathrm{m}$ distal to the trunk dendritic recording site (right). $\boldsymbol{B}$, Example traces for the recording locations shown in $\boldsymbol{A}$ with synaptic input on the branch or the trunk at 40 and $120 \mu \mathrm{m}$ from the soma. C, EPSP amplitude at the trunk dendrite (thick lines) and soma (thin lines) as a function of distance from the soma for synapses located on either the dendritic trunk (purple) or branch (green).

soma. Additionally, because excitatory boutons in the MSO often comprise multiple synapses (Clark, 1969; Russell and Moore, 2002), it is possible that these experiments reflect activation of multiple sites within single presynaptic boutons.

Somatically recorded EPSPs in response to theta electrode minimal stimulation of local excitatory inputs were $\sim 7$ times larger than sEPSPs at the soma (Fig. 1C), suggesting that theta electrode stimulation activated either single boutons with multiple active zones or multiple boutons arising from different branches of afferent fibers (Lindsey, 1975). The slightly larger amplitude of evoked responses near the soma (Fig. 1C) could be explained by the preponderance of larger elongated boutons observed on or near the soma in MSO neurons of gerbils and cats that might reflect more release sites (Clark, 1969; Russell and Moore, 2002). However, we cannot rule out that the larger somatic amplitude reflects a greater difficulty in activating single axons within a larger bundle. Beyond $35 \mu \mathrm{m}$ from the soma, the average amplitude of the minimally stimulated EPSPs was similar regardless of distance (Fig. 1C,D), consistent with our analysis of sEPSPs and paired $\mathrm{Ca}^{2+}$ puff/stimulation experiments.

\section{Influence of dendritic morphology on EPSPs}

The location of synapses along dendrites influences both the amplitude and time course of the activity that reaches the soma and axon (Rall, 1959, 1964). In our experiments, identical simulated EPSC current injections produced progressively larger EPSPs as a function of distance from the soma (Fig. 6G,H), reflecting differences in local passive membrane properties. Our simple compartmental models emphasize that the length, diameter, and especially the taper of the dendrites influence the local dendritic amplitude and, to a lesser extent, the attenuation of EPSPs propagating to the soma. The model also shows that, despite the fact that EPSPs in smaller-diameter dendritic branches can be large, their amplitude at the soma is similar to those originating from the dendritic trunk at the same distance (Fig. 8). These results are consistent with previous studies showing that increased local membrane impedance in relatively narrower distal dendrites can lead to local increases in the amplitude of distal EPSPs, even in the face of uniform synaptic properties (Jaffe and Carnevale, 1999; Williams and Stuart, 2002). Our results are also consistent with a previous voltage-clamp study in MSO neurons showing that dendritic glutamate uncaging gives rise to similar AMPA and NMDA receptor-mediated current changes at the soma independent of distance along the dendrites (Couchman et al., 2012). Together, these findings suggest that morphology plays a major role in reducing the dependence of somatic EPSP amplitude on synapse location in the dendrites (Rinzel and Rall, 1974; Agmon-Snir et al., 1998; Mathews et al., 2010). These results do not preclude the possibility that there might also be a distance-dependent increase in the density of postsynaptic AMPARs in distal dendrites (Magee and Cook, 2000; Andrasfalvy and Magee, 2001; Smith et al., 2003), but implementation of distally increasing linear gradients of synaptic conductances in our compartmental model did not provide a good fit with our experimental results (Fig. 7G,H).

\section{Dendritic cable filtering in MSO dendrites}

Not only was the amplitude of EPSPs at the soma similar for synaptic events initiated at different dendritic locations (Figs. $1 C$, $2 C, 6 C$ ), but the time course was similar as well (Figs. $2 E, F, 4 F$ ). The dendritic membrane time constant is shorter in passive dendritic trees due to the faster current spread away from the synapse, and this effect is more pronounced with further distance from the large capacitive load of the soma (Koch, 1997; Mathews et al., 2010). In addition, MSO principal neurons have a high density of low voltage-activated $(\mathrm{Kv} 1) \mathrm{K}^{+}$channels that are activated by subthreshold EPSPs and provide active repolarization of EPSPs (Svirskis et al., 2003; Scott et al., 2005). As these channels are expressed at threefold higher density in the soma versus the dendrites, active repolarization is most pronounced at the soma, where EPSPs slowed by the effects of cable filtering temporally overlap more extensively with repolarizing $\mathrm{K}^{+}$currents (Mathews et al., 2010; McGinley et al., 2012). By contrast, EPSPs propagating distally from the soma broadened and attenuated less per unit distance (Fig. 5C,F), likely reflecting the combined effects of reduced capacitance, higher impedance, and a lower Kv1 channel density.

HCN channels can also play important roles in normalizing the duration of somatic EPSPs that have propagated from the distal dendrites (Magee, 1998, 1999; Kole et al., 2007). In hippocampal and neocortical pyramidal neurons, distal HCN conductances not only increase the efficiency with which EPSPs propagate to the soma from the distal dendrites, their deactivation during EPSPs provides a net hyperpolarizing influence akin to that described for Kv1 channels in MSO neurons (Stuart and Spruston, 1998; Williams and Stuart, 2000). However, despite the fact that HCN channels are expressed in high density in MSO 
neurons, their role in shaping EPSPs differs from other neuron types because the kinetics of fast AMPAR-mediated EPSPs are at least an order of magnitude faster than the fastest time constant of HCN channel activation (Couchman et al., 2010; Khurana et al., 2012; Baumann et al., 2013). HCN channels thus provide a tonic background conductance, reducing the membrane time constant, and imparting fast intrinsic voltage changes. However, currents through these channels cannot impinge on individual EPSPs or mixed EPSPs/IPSPs, except in a cumulative manner during trains (Khurana et al., 2011; Remme and Rinzel, 2011; Baumann et al., 2013).

\section{Functional implications}

Our findings show that in MSO principal neurons, specialization of dendritic morphology and voltage-gated ion channel expression enable excitatory synapses from all over the dendritic tree to contribute equally to the computation of ITDs. The unavoidable timing delay caused by the limited propagation velocity of the dendrite (Figs. $4 E, 5 E$ ) poses a potential problem for MSO neurons with relatively few independent excitatory inputs. This may be countered by each axon having a more distributed spatial profile with multiple synaptic contacts along the dendrites (Lindsey, 1975). The potential timing drawbacks of spatially distinct dendritic locations are offset by the intrinsic advantages of dendritic synapses: (1) the strong attenuation of EPSPs as they propagate toward the soma reduces the impact of monaural synaptic excitation in the absence of coincident excitation from the opposite dendrite (Mathews et al., 2010); and (2) the distribution of excitatory synapses on separate dendrites can reduce the nonlinear summation of EPSPs arising from reductions in driving force (Agmon-Snir et al., 1998). Indeed, in vivo and in vitro electrophysiological studies have shown that the summation of binaural inputs is remarkably linear over a wide range of stimulus frequencies (van der Heijden et al., 2013; Roberts et al., 2014; Franken et al., 2015; Plauška et al., 2016).

\section{References}

Agmon-Snir H, Carr CE, Rinzel J (1998) The role of dendrites in auditory coincidence detection. Nature 393:268-272. CrossRef Medline

Andrasfalvy BK, Magee JC (2001) Distance-dependent increase in AMPA receptor number in the dendrites of adult hippocampal CA1 pyramidal neurons. J Neurosci 21:9151-9159. Medline

Baumann VJ, Lehnert S, Leibold C, Koch U (2013) Tonotopic organization of the hyperpolarization-activated current (Ih) in the mammalian medial superior olive. Front Neural Circuits 7:117. CrossRef Medline

Beckius GE, Batra R, Oliver DL (1999) Axons from anteroventral cochlear nucleus that terminate in medial superior olive of cat: observations related to delay lines. J Neurosci 19:3146-3161. Medline

Brunso-Bechtold JK, Henkel CK, Linville C (1990) Synaptic organization in the adult ferret medial superior olive. J Comp Neurol 294:389-398. CrossRef Medline

Caicedo A, Eybalin M (1999) Glutamate receptor phenotypes in the auditory brainstem and mid-brain of the developing rat. Eur J Neurosci 11: 51-74. CrossRef Medline

Cant NB, Casseday JH (1986) Projections from the anteroventral cochlear nucleus to the lateral and medial superior olivary nuclei. J Comp Neurol 247:457-476. CrossRef Medline

Clark GM (1969) The ultrastructure of nerve endings in the medial superior olive of cats. Brain Res 14:293-305. CrossRef Medline

Clements JD, Bekkers JM (1997) Detection of spontaneous synaptic events with an optimally scaled template. Biophys J 73:220-229. CrossRef Medline

Couchman K, Grothe B, Felmy F (2010) Medial superior olivary neurons receive surprisingly few excitatory and inhibitory inputs with balanced strength and short-term dynamics. J Neurosci 30:17111-17121. CrossRef Medline

Couchman K, Grothe B, Felmy F (2012) Functional localization of neu- rotransmitter receptors and synaptic inputs to mature neurons of the medial superior olive. J Neurophysiol 107:1186-1198. CrossRef Medline

Franken TP, Roberts MT, Wei L, Golding NL, Joris PX (2015) In vivo coincidence detection in mammalian sound localization generates phase delays. Nat Neurosci 18:444-452. CrossRef Medline

Gardner SM, Trussell LO, Oertel D (2001) Correlation of AMPA receptor subunit composition with synaptic input in the mammalian cochlear nuclei. J Neurosci 21:7428-7437. Medline

Geiger JR, Melcher T, Koh DS, Sakmann B, Seeburg PH, Jonas P, Monyer H (1995) Relative abundance of subunit mRNAs determines gating and $\mathrm{Ca}^{2+}$ permeability of AMPA receptors in principal neurons and interneurons in rat CNS. Neuron 15:193-204. CrossRef Medline

Golding NL, Mickus TJ, Katz Y, Kath WL, Spruston N (2005) Factors mediating powerful voltage attenuation along CA1 pyramidal neuron dendrites. J Physiol 568:69-82. CrossRef Medline

Grothe B (2003) New roles for synaptic inhibition in sound localization. Nat Rev Neurosci 4:540-550. CrossRef Medline

Hines ML, Carnevale NT (1997) The NEURON simulation environment. Neural Comput 9:1179-1209. CrossRef Medline

Jaffe DB, Carnevale NT (1999) Passive normalization of synaptic integration influenced by dendritic architecture. J Neurophysiol 82:3268-3285. Medline

Khurana S, Remme MW, Rinzel J, Golding NL (2011) Dynamic interaction of Ih and IK-LVA during trains of synaptic potentials in principal neurons of the medial superior olive. J Neurosci 31:8936-8947. CrossRef Medline

Khurana S, Liu Z, Lewis AS, Rosa K, Chetkovich D, Golding NL (2012) An essential role for modulation of hyperpolarization-activated current in the development of binaural temporal precision. J Neurosci 32:28142823. CrossRef Medline

Kiss A, Majorossy K (1983) Neuron morphology and synaptic architecture in the medial superior olivary nucleus: light- and electron microscope studies in the cat. Exp Brain Res 52:315-327. Medline

Koch C (1997) Computation and the single neuron. Nature 385:207-210. CrossRef Medline

Kole MH, Letzkus JJ, Stuart GJ (2007) Axon initial segment Kv1 channels control axonal action potential waveform and synaptic efficacy. Neuron 55:633-647. CrossRef Medline

Lindsey BG (1975) Fine structure and distribution of axon terminals from the cochlear nucleus on neurons in the medial superior olivary nucleus of the cat. J Comp Neurol 160:81-103. CrossRef Medline

Lomeli H, Mosbacher J, Melcher T, Höger T, Geiger JR, Kuner T, Monyer H, Higuchi M, Bach A, Seeburg PH (1994) Control of kinetic properties of AMPA receptor channels by nuclear RNA editing. Science 266:17091713. CrossRef Medline

Magee JC (1998) Dendritic hyperpolarization-activated currents modify the integrative properties of hippocampal CAl pyramidal neurons. J Neurosci 18:7613-7624. Medline

Magee JC (1999) Dendritic Ih normalizes temporal summation in hippocampal CA1 neurons. Nat Neurosci 2:848. CrossRef Medline

Magee JC, Cook EP (2000) Somatic EPSP amplitude is independent of synapse location in hippocampal pyramidal neurons. Nat Neurosci 3:895903. CrossRef Medline

Mathews PJ, Jercog PE, Rinzel J, Scott LL, Golding NL (2010) Control of submillisecond synaptic timing in binaural coincidence detectors by Kv1 channels. Nat Neurosci 13:601-609. CrossRef Medline

McGinley MJ, Liberman MC, Bal R, Oertel D (2012) Generating synchrony from the asynchronous: compensation for cochlear traveling wave delays by the dendrites of individual brainstem neurons. J Neurosci 32:93019311. CrossRef Medline

Perkins RE (1973) An electron microscopic study of synaptic organization in the medial superior olive of normal and experimental chinchillas. J Comp Neurol 148:387-415. CrossRef Medline

Plauška A, Borst JG, van der Heijden M (2016) Predicting binaural responses from monaural responses in the gerbil medial superior olive. J Neurophysiol 115:2950-2963. CrossRef Medline

Rall W (1959) Branching dendritic trees and motoneuron membrane resistivity. Exp Neurol 1:491-527. CrossRef Medline

Rall W (1964) Theoretical significance of dendritic trees for neuronal inputoutput relations. In: The theoretical foundation of dendritic function: selected papers of Wilfrid Rall with commentaries (Segev I, Rinzel J, Shephard G, eds), pp 122-146. Cambridge, MA: Massachusetts Institute of Technology. 
Rautenberg PL, Grothe B, Felmy F (2009) Quantification of the threedimensional morphology of coincidence detector neurons in the medial superior olive of gerbils during late postnatal development. J Comp Neurol 517:385-396. CrossRef Medline

Remme MW, Rinzel J (2011) Role of active dendritic conductances in subthreshold input integration. J Comput Neurosci 31:13-30. CrossRef Medline

Rinzel J, Rall W (1974) Transient response in a dendritic neuron model for current injected at one branch. Biophys J 14:759-790. CrossRef Medline

Roberts MT, Seeman SC, Golding NL (2014) The relative contributions of MNTB and LNTB neurons to inhibition in the medial superior olive assessed through single and paired recordings. Front Neural Circuits 8:49. CrossRef Medline

Roth A, Häusser M (2001) Compartmental models of rat cerebellar Purkinje cells based on simultaneous somatic and dendritic patch-clamp recordings. J Physiol 535:445-472. CrossRef Medline

Rothman JS, Manis PB (2003) The roles potassium currents play in regulating the electrical activity of ventral cochlear nucleus neurons. J Neurophysiol 89:3097-3113. CrossRef Medline

Russell FA, Moore DR (2002) Ultrastructural transynaptic effects of unilateral cochlear ablation in the gerbil medial superior olive. Hear Res 173: 43-61. CrossRef Medline

Schmid S, Guthmann A, Ruppersberg JP, Herbert H (2001) Expression of AMPA receptor subunit flip/flop splice variants in the rat auditory brainstem and inferior colliculus. J Comp Neurol 430:160-171. CrossRef Medline

Schmidt-Hieber C, Jonas P, Bischofberger J (2007) Subthreshold dendritic signal processing and coincidence detection in dentate gyrus granule cells. J Neurosci 27:8430-8441. CrossRef Medline

Schofield BR, Cant NB (1991) Organization of the superior olivary complex in the guinea pig: I. Cytoarchitecture, cytochrome oxidase histochemistry, and dendritic morphology. J Comp Neurol 314:645-670. CrossRef Medline

Scott LL, Mathews PJ, Golding NL (2005) Posthearing developmental refinement of temporal processing in principal neurons of the medial superior olive. J Neurosci 25:7887-7895. CrossRef Medline
Scott LL, Mathews PJ, Golding NL (2010) Perisomatic voltage-gated sodium channels actively maintain linear synaptic integration in principal neurons of the medial superior olive. J Neurosci 30:2039-2050. CrossRef Medline

Smith AJ, Owens S, Forsythe ID (2000) Characterisation of inhibitory and excitatory postsynaptic currents of the rat medial superior olive. J Physiol 529:681-698. CrossRef Medline

Smith MA, Ellis-Davies GC, Magee JC (2003) Mechanism of the distancedependent scaling of Schaffer collateral synapses in rat CA1 pyramidal neurons. J Physiol 548:245-258. CrossRef Medline

Smith PH (1995) Structural and functional differences distinguish principal from nonprincipal cells in the guinea pig MSO slice. J Neurophysiol 73: 1653-1667. Medline

Smith PH, Joris PX, Yin TC (1993) Projections of physiologically characterized spherical bushy cell axons from the cochlear nucleus of the cat: evidence for delay lines to the medial superior olive. J Comp Neurol 331: 245-260. CrossRef Medline

Stuart G, Spruston N (1998) Determinants of voltage attenuation in neocortical pyramidal neuron dendrites. J Neurosci 18:3501-3510. Medline

Svirskis G, Dodla R, Rinzel J (2003) Subthreshold outward currents enhance temporal integration in auditory neurons. Biol Cybern 89:333-340. CrossRef Medline

van der Heijden M, Lorteije JA, Plauška A, Roberts MT, Golding NL, Borst JG (2013) Directional hearing by linear summation of binaural inputs at the medial superior olive. Neuron 78:936-948. CrossRef Medline

Williams SR, Stuart GJ (2000) Site independence of EPSP time course is mediated by dendritic $\mathrm{I}(\mathrm{h})$ in neocortical pyramidal neurons. J Neurophysiol 83:3177-3182. Medline

Williams SR, Stuart GJ (2002) Dependence of EPSP efficacy on synapse location in neocortical pyramidal neurons. Science 295:1907-1910. CrossRef Medline

Zhou Y, Carney LH, Colburn HS (2005) A model for interaural time difference sensitivity in the medial superior olive: interaction of excitatory and inhibitory synaptic inputs, channel dynamics, and cellular morphology. J Neurosci 25:3046-3058. CrossRef Medline 